\title{
Evaluation of pathological manifestations in concrete structural floor destined to the operation of vehicles in garage: case study of residential building located in the federal district
}

\author{
Jorge Oliveira $^{1} \cdot$ Manuele Anjos $^{1} \cdot$ Melinna Santos $^{1}$
}

Received: 26 June 2016/ Accepted: 27 October 2016/Published online: 19 November 2016

(C) Springer International Publishing Switzerland 2016

\begin{abstract}
The origin of pathological problems in the structure indicates in general the existence of faults during the execution of a phase of construction, it also indicates faults in the quality control system of one or more activities. The polished concrete floor is a surface subjected to daily traffic of vehicles and the action of chemical substances, in this way should have as main attributes the durability, hardness and strength. This research has the intention to study the case of pathological changes found by polished concrete floor of the garage of the Condomínio Via Parque da Cidade, Setor Sudoeste-Brasília/DF. In addition, the project presents proposals for corrective action identified these pathologies. The same were mainly identified by visual inspection, but is made necessary the building's historical analysis and finally percussion tests, extraction and rupture of the test piece of sample, proving the initial opinion. It could be sure that the observed cracks are due to poor adhesion between layers on the garage floor, as the exacerbation of such problems can be blamed on construction execution addictions. As corrective action is recommended the demolition of the current floor and execution of the entire reconstruction process of the polished concrete floor, according to a new project that has the necessary guidelines to prevent the return of pathology and so there is the performance of recovery the same.
\end{abstract}

Manuele Anjos

manuelealves@hotmail.com

Jorge Oliveira

rafagus@gmail.com

Melinna Santos

melinnasantos@hotmail.com

1 Universidade Católica de Brasília, Federal District, Brasília, Brazil
Keywords Polished floor - Garage - Adherence point Cracks · Pathology · Corrective measures

\section{Introduction}

The polished concrete floor is a complementary part of the building, which should present a number of properties and performance requirements such as durability, hardness and strength, as it is subjected to heavy vehicle traffic and the action of chemicals. This is a type mainly used in large floor areas such as garages, airports, malls, due to the fact that the surface thereof becomes denser, which results in significant gains resistance to abrasion and impact. Furthermore, the concrete floor polishing repairs all irregularities and smoothing the edges of the floorboards.

The development of a project and the use of good quality materials are essential to reduce the possible pathological manifestations and quality control throughout the production process, but do not guarantee the eradication of these problems. Cracks wear and faulted joint, can be classified as the most relevant pathologies identified in polished concrete floors. There are two main types of cracks in the concrete floor, structural and retraction in which distinguish themselves as their derivations and causes the life of the structure. The cracks by retraction categorize in plastic, when there is a relatively quick evaporation of water due to factors such as temperature, relative humidity, water/cement relation and wind speed. According to the magazine Pini [1], the drying shrinkage occurs when the concrete loses moisture, contracting (and when it wins, expands), this volume variation in concrete structures would not be bad if there was freedom of their movement. However, the existence of armor and other factors prevent the mobility of the frame pieces leading to 
the onset of tensile stresses which may burst the concrete, causing the appearance of cracks. Thus, the greater the consumption of cement added to the mixture, water-cement relation and fineness of aggregate, the higher will be the shrinkage. Finally, cracks like "crow's foot" or microcracks are characterized by presenting small depth, narrow opening and small spacing between themselves, generated by the poor fulfillment of the cure, concrete with high fines content and aggregate with excess impurities, provided that exposure (low relative humidity, high temperature, direct sunlight and wind). The structural character of cracks correspond to the preparation of the subgrade and sub-base, due to poor soil compaction designated by the damage stability and floor loading capacity, and can be avoided by performing tests on the ground.

Another condition that is growing increasingly abrading the surface, and according Tarr and Farny [2] that "it is characterized by the formation of pulverulent material on the concrete surface, or the weight loss of the cementitious material. Such pathological manifestation is directly affected by the characteristics of the constituents of the concrete mix materials and their proportioning, the steps of application and the curing procedures." The surface is compromised in terms of resistance and, with the request by abrasion and impact, wear occurs, resulting breaking the edges of the joints, excessive dust formation and all damages resulting from this process. This disorder shows that the active traffic on the floor surface is at odds with the running conditions also some execution addictions can enhance such wear.

In a concrete floor, the joints are not very resistant to impacts, because it must be performed in specific way, and may be subject to faulted joint, that is to say, the edges breaks design errors, such as the adoption of inappropriate diameter transfer bars or erroneous specification of filler material also collaborate to the occurrence of faulted joint. The removal of the transfer bars to facilitate stripping also contributes to the weakening of the joints and mistakes in the positioning of the same (shaft inappropriate) can create cracks close to these sites.

Another relevant aspect to the appearance of pathological manifestations is the poor adhesion between the new and old concrete, which are usually performed incorrectly. Marek and Vanderlei [3], claim that often the contact region between the concrete of different ages is the site most prone to the emergence of problems because in addition to being the region with the highest risk of segregation of materials is also region where it's more usual arise laitance layers, which act as a layer of low resistance and decreasing adhesion between the two concretes. Thus, the construction of a bonding bridge it is necessary that in addition to allowing a complete adhesion between repair and concrete substrate also serves as a protective layer for the restored area.

The construction elements require maintenance over time, because it's natural wear of the materials, but in some cases there may be flaws, described as constructive defects, which according to NBR 13752/1996 [4] these are "anomalies that affect the performance of products or services or make them unsuited to the purposes for which they are intended, causing property damage or inconvenience to the consumer. May be due to design flaw, or execution or the faulty information about operation and maintenance." Therefore, constructive addictions are all constructive failures that cause material injury to the consumer and that imply financial costs to repair them.

Therefore, the incentive for this case study was the result of pathological manifestations presented in structural concrete for the circulation of vehicles in the garage of the building Via Parque da Cidade, located in the Setor Sudoeste-Brasilia/DF, which are related to poor adhesion between this floor layers causing cracks in it. Refers to a 6 floors building with 10 apartments per floor, the common area consists of ground floor, basement with 176 parking spaces, 5 elevators boxes and stairs, collective coverage and playground. It is approximately 11 years of age, the structure was executed in reinforced concrete and the basement floor made of polished concrete.

\section{Methods}

\subsection{Preliminary inspection}

\subsubsection{Historic building survey}

The survey of information generally becomes important later to follow a strand of which necessary tests to a relevant conclusion. In view of this, it were reported apartment manager, residents and employees testimonials, which reported that the major problem underground floor (garage) is the appearance of fissures and cracks in the whole area of the polished concrete floor (about $3521.63 \mathrm{~m}^{2}$, deducting the area of the pillars), moreover in some cases arose gaps between the concrete slabs that could be felt when crossing with cars. It was also reported that held a corrective maintenance at points located in the underground floor which had flaking, where approximately $290 \mathrm{~m}^{2}$ floor were exchanged for a new one with added fiber, but this new floor again presented similar conditions the present in the rest of the garage. In addition, inferred the technical documentation, like plant designs and drawings, for further inspection. 


\subsubsection{Visual analysis}

Subsequent to the survey in place of the definition of general and specific characteristics of the building, the pathological manifestations have been identified mainly through visual inspection. The predominant pathology observed were cracks and crevices around the floor of garage, as shown in Figs. 1, 2, 3, 4, 5 and 6. In view that in Fig. 6 there are not many cracks on the granite floor of the garage elevator lobby, since there is no vehicle traffic.

\subsection{Tests performed}

\subsubsection{Percussion test}

The percussion test is to detect and map out possible flaws in the affected area, thus being able to develop a solution scope to the problem and ensure the durability of building and safety of residents. The same was done across the entire garage floor of the study, inasmuch as this floor had cracks and hollow sound across the entire surface, this test is qualified to identify symptoms and ascertain the existence of anomalies, being relevant to this research. Using a metal rod to which were granted blows the entire length of the garage, except in locations where they parked cars in order to identify the locations that were hollow sound, showing where probably the floor was peeling and there was a good soil compaction. During the test it was found that most of the places that had cracks and fissures were just the places where the sound was hollow, however there were not places without cracks/fissures apparent that also had the same sound. The execution of the procedure can be seen in Figs. 7 and 8.

\subsubsection{Extraction and disruption samples of test specimens}

Guided by the sketch prepared after the percussion test, opted for extraction of 8 samples in the floor, four in areas that had hollow sound and 4 in areas that don't have this

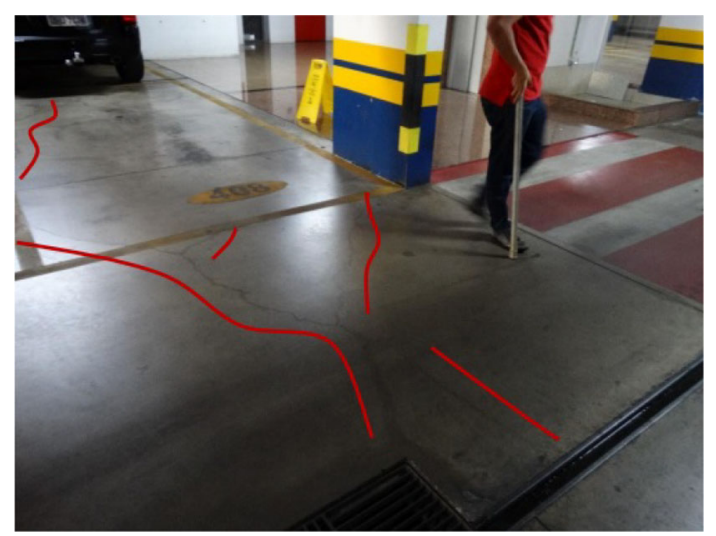

Fig. 1 Cracks in the garage floor sound. Then, these eight samples were taken two samples located on the floor which was executed as a corrective measure, one in the area with hollow sound and 1 in the area without hollow sound. For the extraction it was used a drilling machine with $100 \mathrm{~mm}$ diamond bur according to NBR 7680/2015 [5] and disruption used a hydraulic press PCE100 according to NBR 5739/2007 [6]. As part of the specimens were extracted with the layers separated, it was

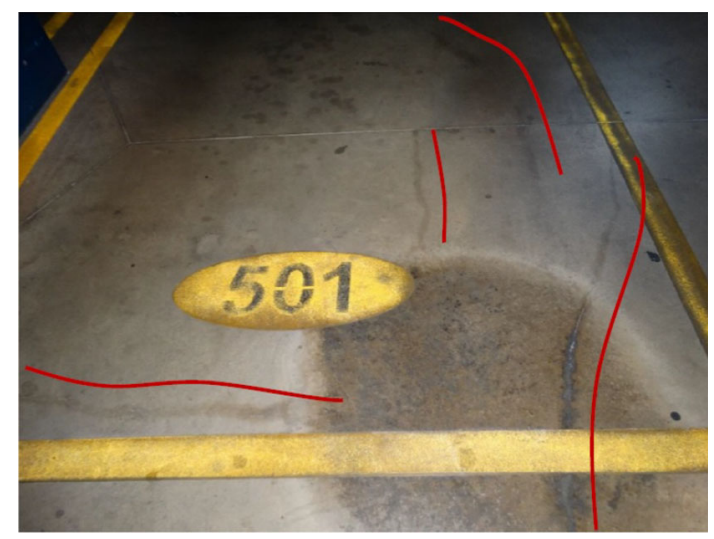

Fig. 2 Cracks in the garage floor

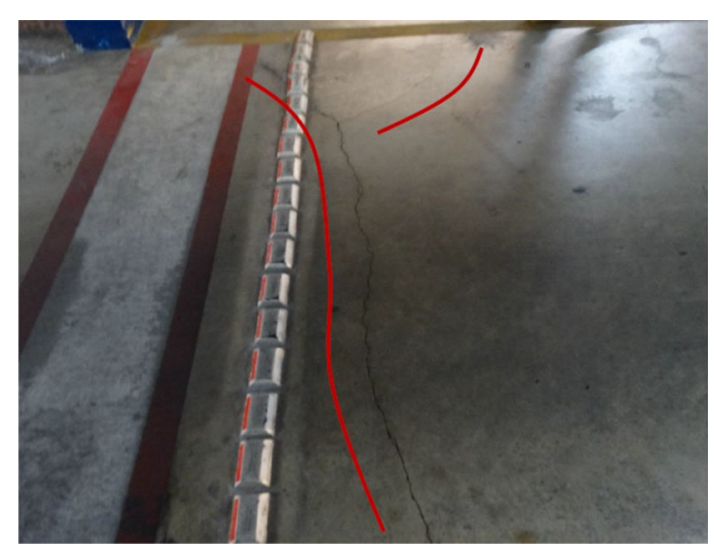

Fig. 3 Cracks in the garage floor

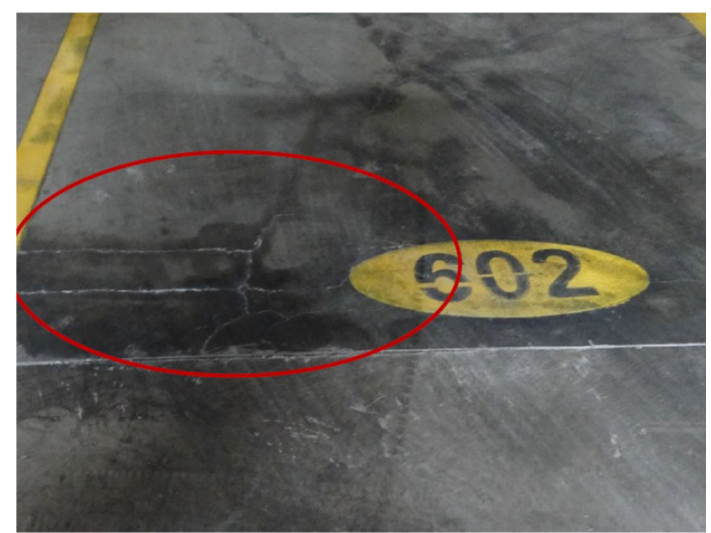

Fig. 4 Cracks in the garage floor 


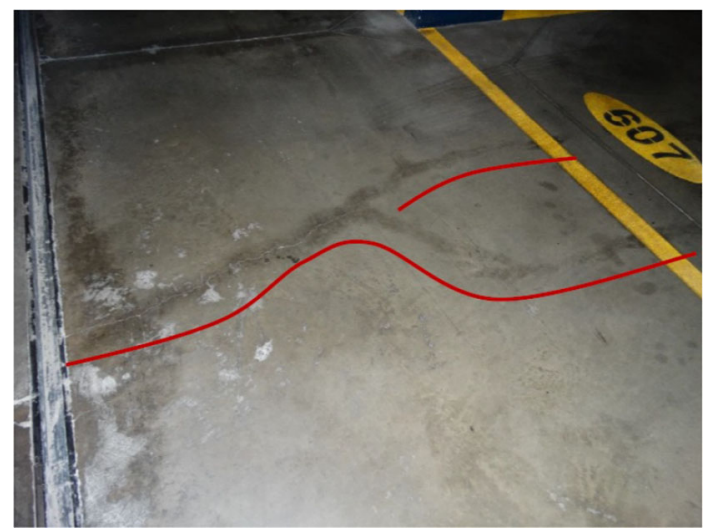

Fig. 5 Cracks in the garage floor

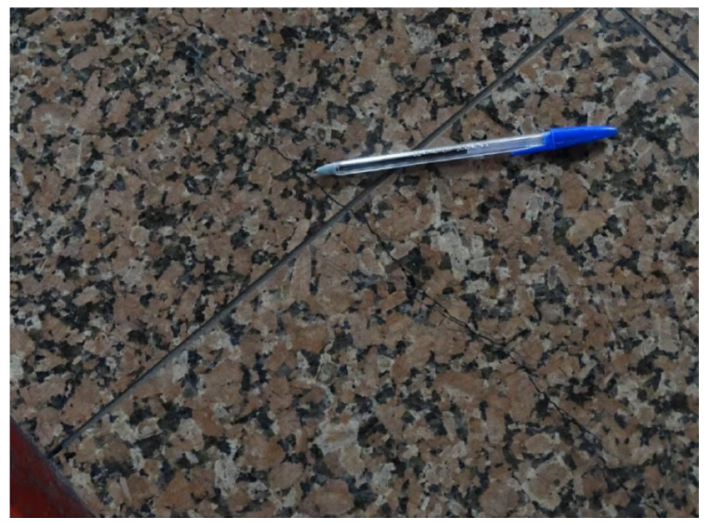

Fig. 6 Cracks and fissures in the granite floor of the elevator hall in the garage

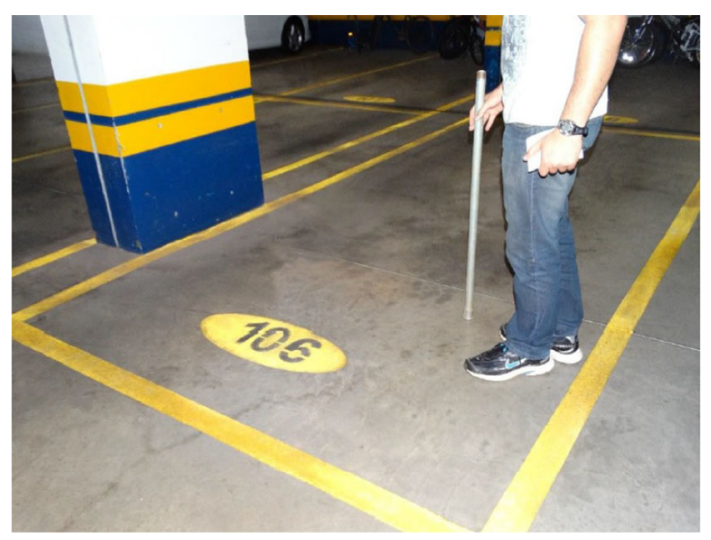

Fig. 7 Realization of percussion test

not possible disruption thereof, therefore it was only broken the three samples that were integers (Fig. 9).

Figure 10 depicts the sample extracted from areas that showed hollow sounds and Fig. 11 represents a sample of the areas that showed no such sound (Fig. 12). Already in Figs. 13 and 14 it is clear that the form of specimen rupture started at the interface between the layers, thus showing the lack of adherence bridge.

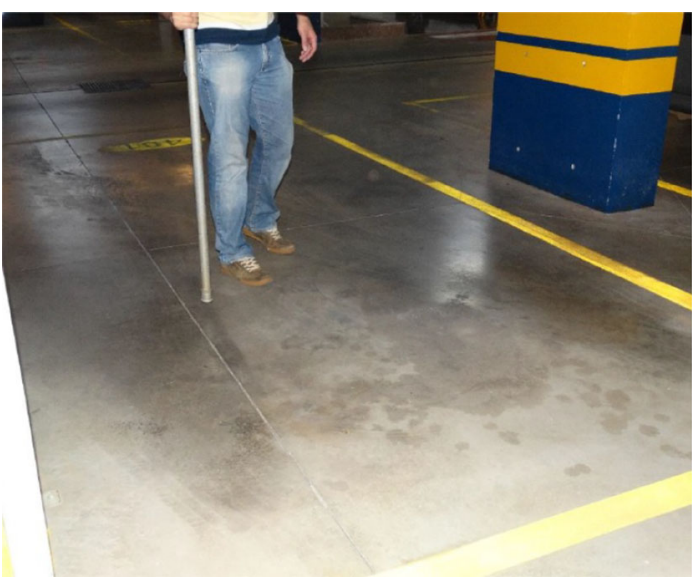

Fig. 8 Realization of percussion test

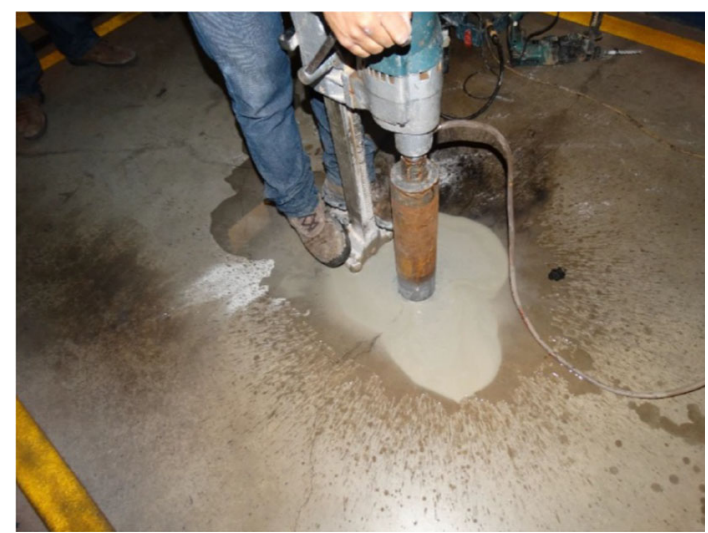

Fig. 9 Extraction of specimen sample

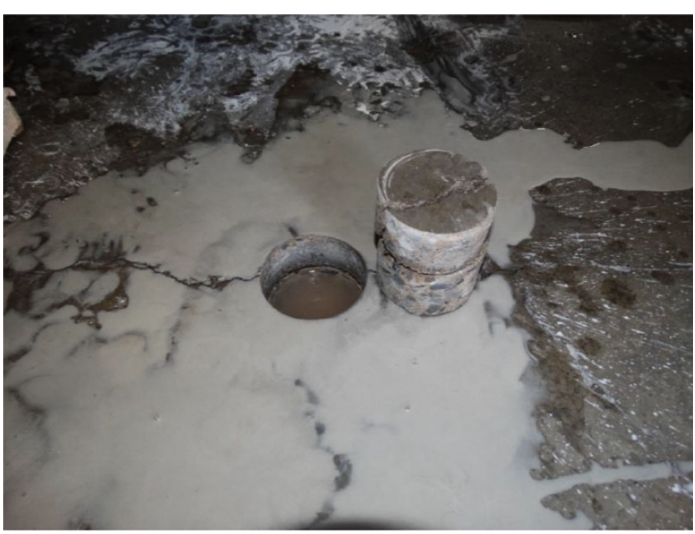

Fig. 10 Sample of areas with hollow sound

\section{Analysis of data and results}

The pathological manifestations found were subdivided according to the degree of risk that offer for the building, to their users and the environment, they are classified as:

Critical When there is excessive loss of performance causing possible outages causing damage to the health and 


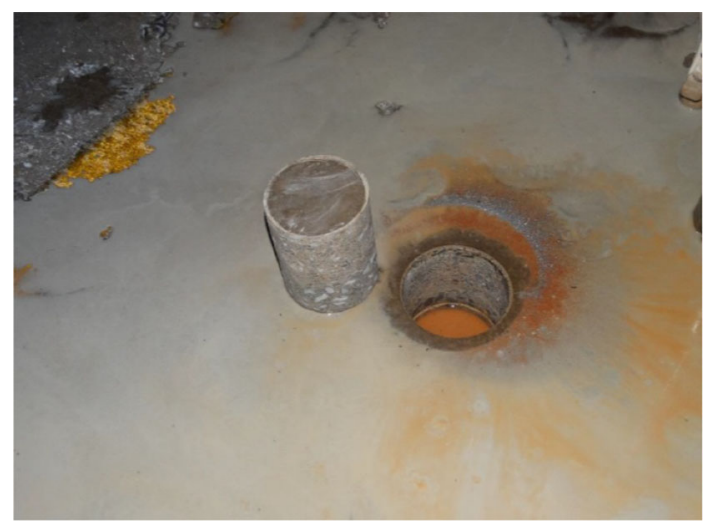

Fig. 11 Sample of areas without hollow sound

Fig. 12 Disruption of the sample with the use of hydraulic press

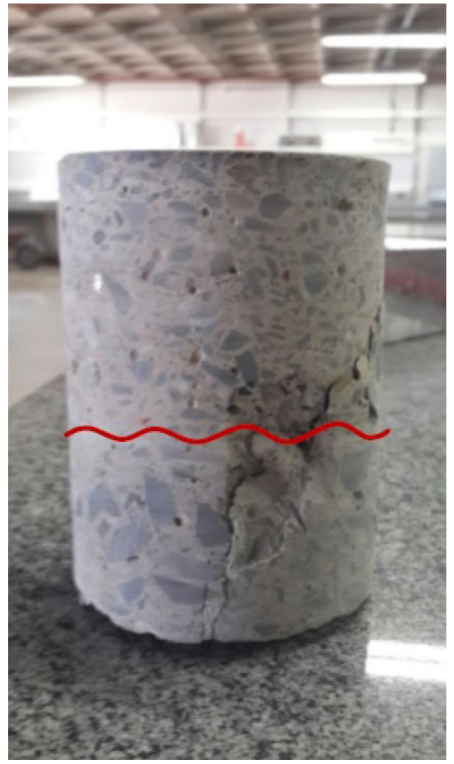

Fig. 13 Disruption of sample

safety of people and/or the environment, cost increase, compromising the service life and sharp devaluation.

Regular Can cause loss of functionality without prejudice to the direct operating systems, timely performance loss, early deterioration and small devaluation.

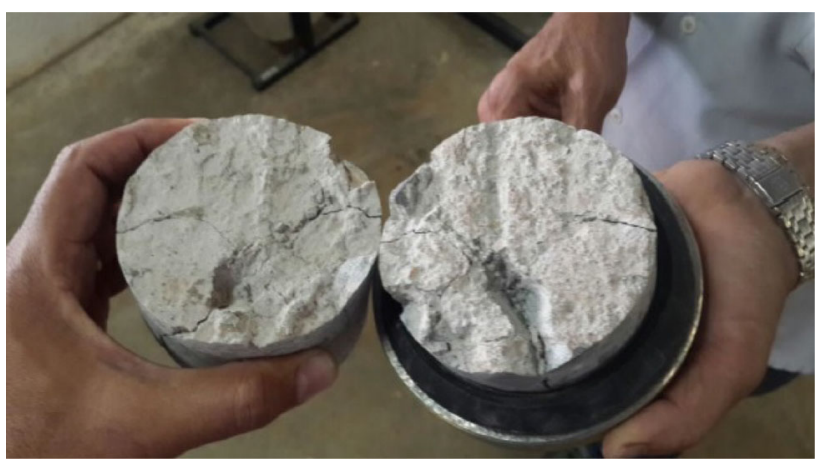

Fig. 14 Disruption of sample

Minimum May cause minor damage to the aesthetics or programmable activity and planned without incidence or without the likelihood of critical and regular risk, and low or no impairment of real estate value.

After the percussion test was prepared a detailed sketch of the floor indicating the dimension of the floor under consideration as shown in Fig. 15, then another sketch was also made to indicate all points that were hollow sound, as shown in Fig. 16.

According to the sketch drawing performed after the percussion test, it was observed that the garage floor has hollow sounds generalized manner throughout the area. Furthermore, after extracting the samples, Fig. 16, was found differences in thicknesses between the concrete layer, therefore can attest that the materials used in each layer are different, since there is difference in the particle size of the coarse aggregate and the color difference confirms that the layers have been performed at different times, such as seen in Fig. 17.

Analyzing the samples extracted from areas where the sound is hollow, was evident that there was no adhesion between the two layers, because when removing the same from the drill, layers were separated. In just a sample where the sound was not hollow was detected poor adhesion of the layers. In some samples were found soil traces between the layers, showing that it has not taken the required cleaning for the preparation of adhesion bridge between the two concrete divisions (Fig. 18).

In the samples extracted from areas with new floor it was observed that the lower layer earlier, was maintained and only the upper layer was re-executed. Both layers of the new floor areas presented the same characteristics and pathological manifestations of the garage remainder. During the visual inspection of the samples, it has been certified that there was steel armor on both layers. However, especially in the lower floor, armor height varied from one sample to another, sometimes over, sometimes low and sometimes in the middle of the layer, in some cases without any concrete cover, showing that not used spacers to 


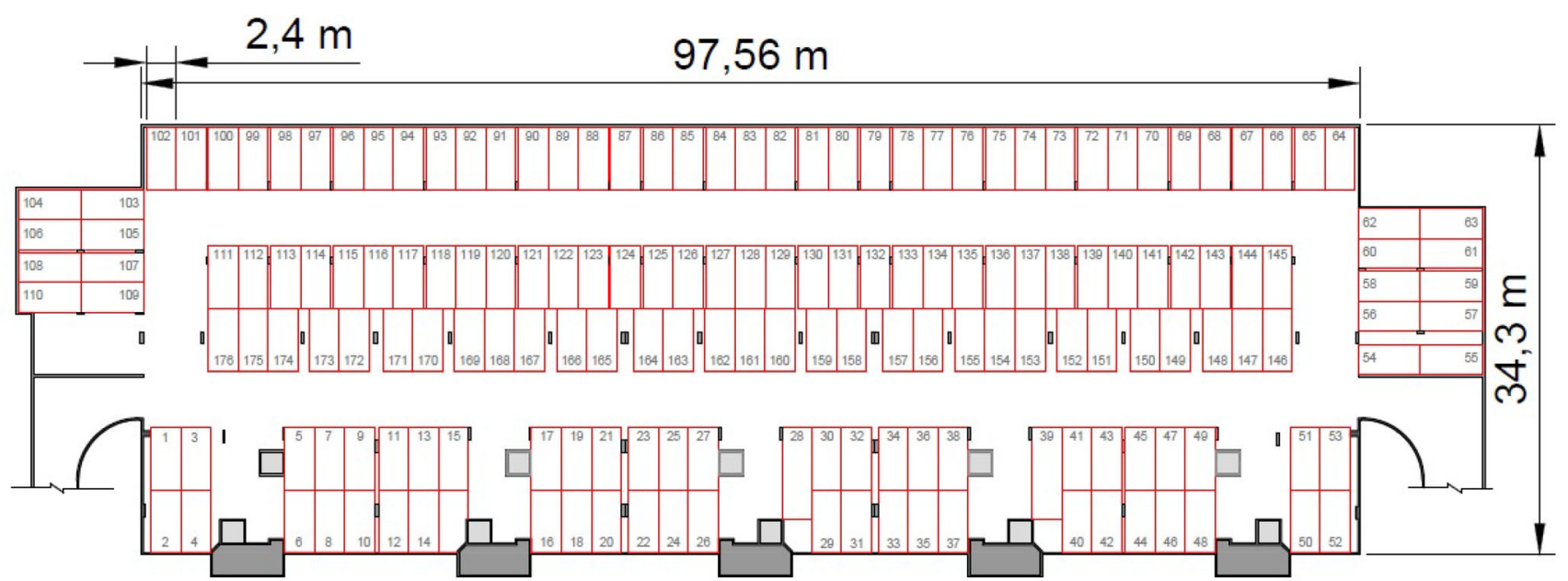

PLANTA BAIXA - SUBSOLO

LEGENDA:

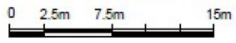

$\square$ CAIXA DO ELEVADOR

$\square$ CAIXADE ESCADA

Fig. 15 Sketch detailing the floor dimensions

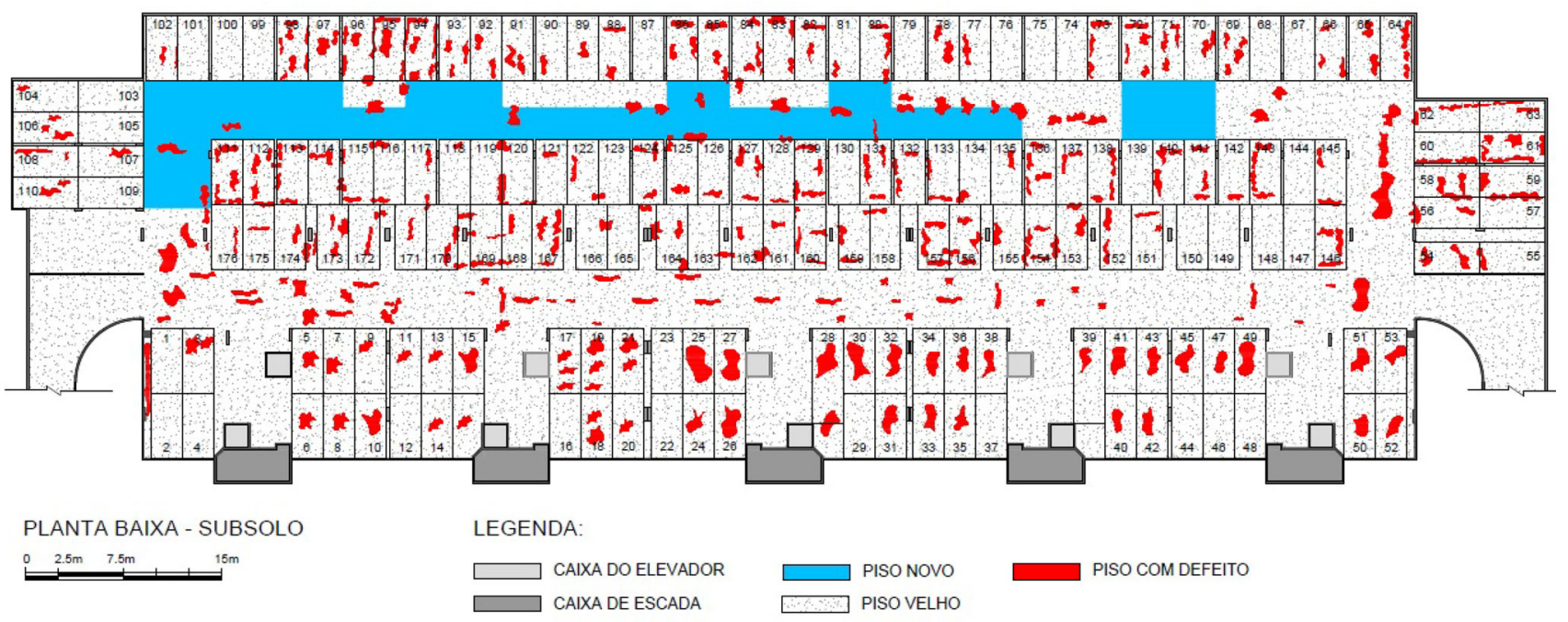

Fig. 16 Sketch detailing all the points that have hollow sound

maintain the height concrete cover, it would be necessary to ensure the protection of steel bars against corrosion.

\section{Conclusions and recommendations}

Through the data inspection obtained in the performed tests it was found, that the pathological manifestations of cracks/fissures and existing flaking on the garage floor are related to poor adhesion between the layers, since it is not ideal the realization of two concreting layers at different times, being relevant the execution of a single layer of concrete, and has not been performed the required cleaning for the preparation of the adherence bridge. Overall, the worsening of these pathological manifestations can be attributed to construction addiction of execution or lack of a detailed project with technical descriptions necessary to the floor execution.

The risk of the pathology in question was characterized as regular as it presents no risk to the health and safety of users and/or the environment, however it shows a total loss of performance, early deterioration and small devaluation of the property.

In view of the opinion accomplished, suggested the demolition of all the existing floor, soil recompaction or withdrawal of the old soil and compaction of a new one, application of separating layers through PVC film (plastic sheeting), using double steel mesh of at least $4.2 \mathrm{~mm}$ in 


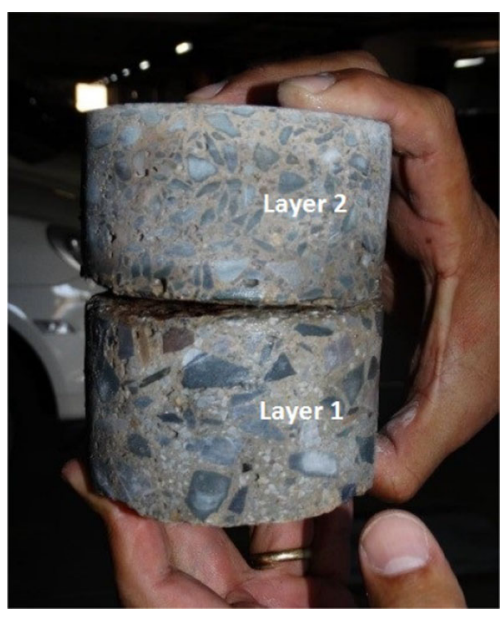

Fig. 17 Fig 16-Area of sample with hollow sound

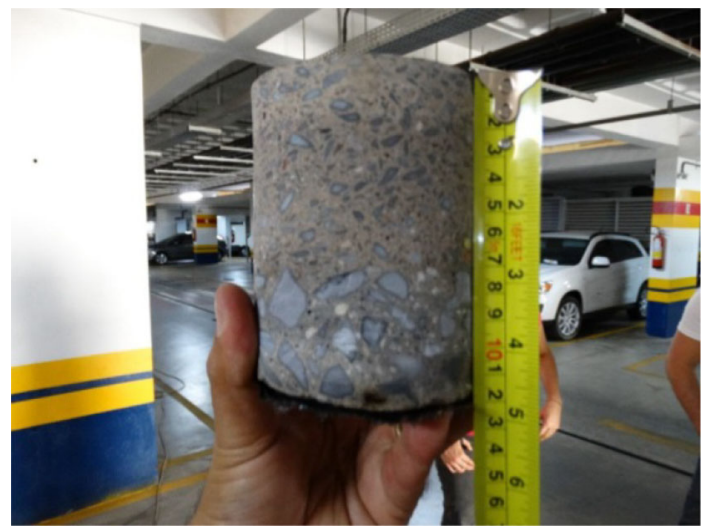

Fig. 18 Area of sample without hollow sound

diameter with spacers and concreting and polishing of a new floor, in order to give users the same performance that is observed in the rest of the building. It is worth noting the importance of implementing correctly the desolidarisation joints and movement.

The basis of the performance of reinforced concrete with fibers is the role exerted by the tension transfer bridge by the cracks. In plain concrete, a crack is a barrier to the propagation of stress, which causes a stress concentration at the edge of the crack. The tensile stress transfer bridge work that fiber carries through the cracks in the concrete is a very interesting mechanism of energy increase associated with rupture of the material and the restriction on the development of cracks. That way, recommend the application of fibers in concrete to be used for the new floor execution, since the fibers decrease the cracks spread speed, and the concrete is replaced by a ductile behavior and increases the tensile strength.

\section{References}

1. Pini (2010) Quais as causas de fissuras em concreto? Revista Pini

2. Tarr SM, Farny JA (2008) Concrete floors on ground. Portland Cement Association, Skokie

3. Marek Filho CAM, Vanderlei RD (2007) Estudo das ligações entre concretos de diferentes propriedades solicitados à flexão pura, I Seminário de Engenharia Urbana da Universidade Estadual de Maringá, Maringá. pp 163-173

4. Associação Brasileira de Normas Técnicas (1996) NBR 13752Perícias de engenharia na construção civil

5. Associação Brasileira de Normas Técnicas (2015) NBR 7880-1 (Versão Corrigida: 2015)—Concreto—Extração, preparo, ensaio e análise de testemunhos de estruturas de concreto. Parte 1: Resistência à compressão axial

6. Associação Brasileira de Normas Técnicas (2007) NBR 5739Concreto-Ensaios de compressão de corpos-de-prova cilíndricos 